Student Success

ISSN: 2205-0795

Volume 8, Issue 2, pp. 107-111

J uly 2017

\title{
Let's Chat - A fresh take on the invaluable role of peer-to- peer conversation in student engagement, participation and inclusion
}

\author{
Rosalind McFarlane, Marta Spes-Skrbis and Anne Taib \\ Monash University, Melbourne, Australia
}

\begin{abstract}
*
This session reports on Monash University's recently developed Let's Chat program, delivered at three campuses as a modularised, peer learning opportunity for students from first year to PhD. Involving 3,591 student participants and facilitators in 2015 and 2016, the program responds directly to student feedback and recommendations. Let's Chat maximises opportunities for peer-to-peer interaction with the aim of increasing participants' confidence and competence in spoken English and intercultural communication. Informed by current trends in student-centred and peer-assisted learning theory, TESOL and intercultural communication, Let's Chat is quickly establishing itself as an effective approach to supporting student participation, engagement and sense of belonging in diverse teaching and learning contexts and communities. The session presents a snapshot of the genesis of the program; an evaluation of its implementation; and a summary of emerging outcomes. The session also engages participants in a conversation about how this model might be replicated in other settings.
\end{abstract}

*This 'Emerging Initiative' was first presented at the 2017 STARS Conference in Adelaide, Australia in July 2017 and was selected by the Conference Committee as one of the top-rated reports. The authors have kindly given their permission to have this report published in this special issue of the Journal and it has undergone a further review by the editors to confirm it aligns with the Journal format.

Please cite this article as:

McFarlane, R., Spes-Skrbis, M., \& Taib, A. (2017). Let's Chat - A fresh take on the invaluable role of peer-to-peer conversation in student engagement, participation and inclusion. Student Success, 8(2), 107-111. doi: 10.5204/ssj.v8i2.388

This practice report has been accepted for publication in Student Success. Please see the Editorial Policies under the 'About' section of the Journal website for further information.

Student Success: A journal exploring the experiences of students in tertiary education cc) (i) articles are free to use, with proper attribution, in educational and other non-commercial settings. ISSN: 2205-0795 


\section{Context}

Focus Monash: Strategic Plan 2015-2020 (n.d.) identifies inclusion as an institutional goal and calls for the development of co-curricular activities and initiatives which will enhance the student experience and lead to a strong sense of belonging and connection. The plan explicitly identifies intercultural competence as a hallmark of Monash education. Improving campus-based engagement outcomes, inculcating intercultural competence through curriculum and pedagogy, and providing a variety of opportunities for English language development are all identified as enabling strategies. The co-curricular project English Connect (n.d.) and more specifically the Let's Chat program have emerged in the last two years in response to these strategic directions.

\section{The development of conversational approach}

Situated within the Campus Community Division, the small English Connect team is aligned with a number of innovative student experience projects. This proximity, coupled with the team's expertise in English Language education and intercultural studies, has enabled a fresh interpretation of some wellestablished approaches. Drawing first on the fundamental principles of Communicative Competence (Canale \& Swain, 1980; Crystal,1997) as well as Krashen's Input Theory $(1987,1988)$, the team turned to arguably the most important stakeholders of all for ideas on how to structure the program the students. Commissioned to create learning opportunities for the development of English language and intercultural competence in the co-curricular space, the English Connect team entered into a series of semi structured conversations with 74 students from a range of cohorts in a series of focus groups which explored their perceptions and preferences. Overwhelmingly, the respondents asked for the opportunity to meet with and talk to their peers of other language and cultural backgrounds - in short, to practice and extend their current communication skills and take risks in a safe and supported social environment. This is consistent with research by Devlin, Kift, Nelson, Smith and McKay (2012), who argue that the peer relationships are an important aspect of belonging for students.

Drawing upon the research that has examined peer to peer programs (Adam, Skalicky, \& Brown, 2011; Biggs, 2003; Ramsden, 1992; Topping, 1996) and following accepted practice in Peer Assisted Learning (PAL) programs as a guide, a pilot Let's Chat program was designed incorporating student facilitators to be employed casually at the Higher Education Worker (HEW) Level 3. Twenty positions were advertised. 1000 expressions of interest were received from potential student facilitators. First semester registrations for the program, and the passion for creating a sense of community that came from the facilitators, indicated that desire for interaction and a sense of belonging among peers was important to both international and domestic student cohorts.

\section{An evolving program and methodology}

The Let's Chat program at Monash explicitly uses a conversation model in its design, through the initial creation in focus groups to the continual revising and restructuring of modules based on student and facilitator feedback, as well as in the delivery of Let's Chat classes. Students attend for one hour per week for between 9 and 12 weeks for a highly interactive session structured around themes, role plays, games and discussion. A feature of the program is its flexibility and openness to questions and exchange. 
Masters by coursework students are the majority of Let's Chat students with undergraduates forming the second largest group. For the program's purposes, this cohort share many of the same daily experiences at university, including attending lectures and tutorials, sitting exams, and interactions with lecturers and other academics. As a result of these common experiences, students from both degree types attend the same lessons. Drawing on research by Kift (2009) and James, Krause, and Jennings (2010) which notes the importance of having programs available from first year onward, the initial Let's Chat modules are designed around transition and the firstyear experience, before advancing to themes such as employability that are more relevant for students in later year studies.

Each lesson has been designed to explore a different theme, but has also been specifically tailored to be highly interactive and to investigate communication from a shared space of co-creation, something which reflects the social nature of learning (McConnell, 2006). There are three facilitators in each class and all facilitators are Monash students who have undergone a rigorous selection and training program. The peer learning element of Let's Chat allows for lessons to be less hierarchical and to instead closely resemble a conversation between peers.

Students and facilitators are encouraged to explore different cultural situations and discuss behaviours in a way that allows for cocreation. Facilitators are encouraged to draw on their own experiences as well as those of the students when running activities. Different cultural situations are explored in a way that invites participation from all parties and are designed to be inclusive as they elicit information from all students who may have very different experiences or opinions, even if from similar backgrounds. Further, it enables a site of co-creation as both students and facilitators explore situations together.

\section{Evidence of impact}

The growth in the scale of delivery, now across four campuses, and the rate of re-enrolment into the program attest to the success of Let's Chat. Forty-one separate Let's Chat classes are due to commence in semester 1, 2017. Pre- and post-program self-assessment data collated over four semesters indicate a strong pattern of improvement among student participants, particularly in confidence, participation and engagement with other curricular aspects of the Monash experience. Another strong indicator of success is the engagement and collaboration of Faculties with the Let's Chat program. Some Faculties and Schools such as Pharmacy have collaborated with the Let's Chat team to develop customised modules which allow students to practise relevant communication skills. As well as the student attendees of the Let's Chat program, student facilitators also report significant benefits to their participation in the program through the structures of training, feedback, and mentoring.

\section{STARS Session outcomes}

The 2017 STARS Conference session presented the above information while also discussing three key findings from the 2015 pilot year: (1) that there was a large demand for informal English speaking and listening skills; (2) that $\mathrm{PhD}$ and research students desired a version of the program designed for their needs and; (3) the necessity for a module of Let's Chat that focused on the transition out of university to employment.

Another aspect the session highlighted was how the conversation model was used to build a program. Part of this design has been a balance between learning outcomes and flexibility through design. Having a set of learning outcomes and differentiating the modules of Let's Chat allows students to map their learning around different skills while 
seeing how their language and cultural competency are improving. Facilitators are required to follow the activities and learning directions of each lesson, but are given flexibility regarding how they choose to deliver or tailor these activities to their particular class. Facilitators are given specific training in how to modify lessons to suit different cohorts and class preferences, allowing the students in classes to identify areas of interest and concern that they wish to explore, and giving these students the ownership of their own class to direct this kind of response.

The outcomes regarding students' selfevaluation of their transition were presented, including those showing (a) that $49.6 \%$ of students in Let's Chat are in their first six months in Australia (the key time for transition programs); (b) that students say they feel their transition to Monash and Australia is made considerably easier through participation in the program; and (c) that by the end of the program students feel significantly more accepted by students at the university. Although Let's Chat is not part of a faculty curriculum, students report that their ability to undertake academic study-including understanding lectures and participating in interactive tutorial discussion-is improved through participation in the program.

Questions and comments from session participants focused on how facilitators work within the program, particularly the ways in which English Connect facilitators complete yearly appraisals with the opportunity for promotion into leadership roles with higher pay. Participants emphasised the importance of having professional development through peer-to-peer programs. Questions were also asked about how facilitators provide feedback on their classes, particularly in a large program. Currently Let's Chat facilitators work in teams of three and the team reports every week on each lesson regarding lesson content, lesson delivery and teamwork, thereby providing feedback that is used by the program coordinator to better design the programs. Further, this feedback often reveals areas in which facilitators might benefit from additional training, or new directions the program may take. These strategies allow facilitators to directly impact new parts of the program as well as take ownership of their own professional development, through their own reflection and in specific training.

Session participants discussed the gap between international and domestic students at universities as many students report they feel the cohorts can remain relatively separate. The Let's Chat program was seen by some participants as contributing to improving this issue in a peer-to-peer setting. Of particular interest to the session audience was the idea of having the Let's Chat program structured as classes, as many sessions participants teach within one-on-one mentoring services and the Let's Chat model provided a different kind of engagement that could be used alongside mentoring.

Overall, the session emphasised the importance of student-directed programs in university settings which cater to diverse student cohorts by having well-structured educational design as well as inbuilt responsiveness, allowing programs to grow and change with the cohorts they engage.

\section{References}

Adam, A. Skalicky, J., \& Brown, N. (2011). Planning sustainable peer learning programs: an application and reflection. The International Journal of the First Year in Higher Education, 2(2), 9-22. http://dx.doi.org/10.5204/intjfyhe.v2i2.81

Biggs, J. (2003). Teaching for quality learning at university (2nd ed.). Maidenhead, UK: The Society for Research into Higher Education \& Open University Press.

Canale, M., \& Swain, M. (1980). Theoretical bases of communicative approaches to second language 
teaching and testing. Applied Linguistics, 1(1) 1-47. https://doi.org/10.1093/applin/I.1.1

Crystal, D. (1997). The Cambridge encyclopedia of language. Cambridge, UK: Cambridge University Press.

Devlin, M., Kift, S., Nelson, K., Smith, L., \& McKay, J. (2012). Effective teaching and support of students from low socioeconomic status background: Practical advice for institutional policymakers and leaders. Retrieved from Effective teaching and support of students from low socioeconomic status background website http://www.lowses.edu.au/assets/Practical\%20Adv ice $\% 20$ for $\% 20$ Institutional $\% 20$ Policy $\% 20$ Makers $\%$ 20and\%20Leaders.pdf

English Connect. (n.d.) Monash University. Retrieved from Monash University website https://www.monash.edu/English-connect

James, R., Krause, K., \& Jennings, C. (2010). The First Year Experience in Australian Universities: Findings from 1994 to 2009. Retrieved from the Melbourne Centre for the Study of Higher Education http://melbournecshe.unimelb.edu.au/ data/assets/ pdf file/0010/1670176/FYE Report 1994 to 2009. pdf

Kift, S. (2009). Articulating a transition pedagogy to scaffold and enhance the first year learning experience in Australian higher education: Final report for ALTC Senior Fellowship Program. Australian Learning and Teaching Council, Sydney, Australia. Retrieved from http://transitionpedagogy.com/wpcontent/uploads/2014/05/Kift-Sally-ALTC-SeniorFellowship-Report-Sep-09.pdf

Krashen, S. D. (1987). Principles and practice in second language acquisition. Englewood Cliffs, N.J.: PrenticeHall International.

Krashen, S. D. (1988). Second language acquisition and second language learning. Englewood Cliffs, N.J.: Prentice-Hall International.

McConnell, D. (2006). E-learning groups and communities: imagining learning in the age of the internet. Buckingham, UK: Open University Press.

Focus Monash: Strategic Plan 2015-2020. (n.d.). Monash University. Retrieved from Monash University website

http://www.monash.edu/ data/assets/pdf file/00 04/169744/strategic-plan-printversion.pdf?utm source=webpage\&utm medium $=b u$ tton\&utm campaign=strategicplan

Ramsden, P. (1992). Learning to teach in higher education. London: Routledge.

Topping, K. (1996). The effectiveness of peer tutoring in further and higher education: A typology and review of the literature. Higher Education, 32(3), 321-345. Retrieved

from https://link.springer.com/journal/10734 